\title{
CORRIGENDUM
}

\section{Latin America: the next region for haematopoietic transplant progress}

G Jaimovich, J Martinez Rolon, H Baldomero, M Rivas, I Hanesman, L Bouzas, C Bonfim, J Palma, A Kardus-Urueta, D Ubidia, W Bujan-Boza, O Gonzalez-Ramella, G Ruiz-Argüelles, D Gomez-Almaguer, G Espino, E Fanilla, D Gonzalez, A Carrasco, S Galeano, G Borelli, M Hernandez-Gimenez, M Pasquini, Y Kodera, A Gratwohl, M Gratwohl, J Nuñez, J Szer, RP Gale, D Niederwieser and A Seber

Bone Marrow Transplantation (2017) 52, 798; doi:10.1038/bmt.2017.48

Correction to: Bone Marrow Transplantation (2017) 52, 671-677; doi:10.1038/bmt.2016.361; published online 23 January 2017

Since the online publication of this article, the authors realised there were errors in the legends for Figures 1 and 2.

The original legend for Figure 1 was: 'Reasons for auto (left) $(N=2057)$ and allotransplants (right) $(N=1206)$.' The correct text is: 'Reasons for allotransplants (left) $(N=1206)$ and auto (right) $(N=2057)$.'
The original legend for Figure 2 was: 'Transplant rate. Transplants per 10 (a), autotransplants; b, allotransplants.' The correct text is 'Transplant rate (transplants per 10 million population) (a) autotransplants; (b) allotransplants.'

The authors apologise for any inconvenience caused by these errors.

These errors have now been rectified and the corrected article appears in this issue. The html and online pdf versions have also been rectified, and now carry the corrected paper. 